\title{
The Standard Deviation of Life-Length, Retirement Incentives, and Optimal Pension Design
}

\author{
Thomas Aronsson \\ Sören Blomquist
}

CESIFo Working PAPER No. 3201 Category 1: Public Finance

OCTOBER 2010

\footnotetext{
An electronic version of the paper may be downloaded

- from the SSRN website:

- from the RePEc website: www.SSRN.com

Www.RePEc.org

- from the CESifo website:

www.CESifo-group.org/wp
} 


\title{
The Standard Deviation of Life-Length, Retirement Incentives, and Optimal Pension Design
}

\begin{abstract}
In this paper, we consider how the retirement age as well as a tax financed pension system ought to respond to a change in the standard deviation of the length of life. In a first best framework, where a benevolent government exercises perfect control over the individuals' labor supply and retirement-decisions, the results show that a decrease in the standard deviation of life-length leads to an increase in the optimal retirement age and vice versa, if the preferences for "the number of years spent in retirement" are characterized by constant or decreasing absolute risk aversion. A similar result follows in a second best setting, where the government raises revenue via a proportional tax (or pension fee) to finance a lump-sum benefit per year spent in retirement. We consider two versions of this model, one with a mandatory retirement age decided upon by the government and the other where the retirement age is a private decision-variable.
\end{abstract}

JEL-Code: D61, D80, H21, H55.

Keywords: uncertain lifetime, retirement, pension system.

Thomas Aronsson

Department of Economics

Umeå University

Sweden - 90187 Umeå

Thomas.Aronsson@umu.se
Sören Blomquist

Department of Economics

Uppsala University

Sweden - 75120 Uppsala

Soren.Blomquist@nek.uu.se

September 2010

The authors would like to thank Henry Ohlsson and Tomas Sjögren for helpful comments and suggestions. Research grants from the Bank of Sweden Tercentenary Foundation, the Swedish Council for Working Life and Social Research, and the National Tax Board are gratefully acknowledged. 


\section{Introduction}

In 1913, the Swedish parliament decided upon a general public pension. The retirement age was set to 67. At that time, the expected life-length was 55 years, implying that the expected length of life fell short of the retirement age by 12 years. According to these rules, and the average length of life at the time, most people would never benefit from the public pension system. Since then, the expected length of life has increased considerably and was 81 years in 2008 for Sweden. Similar increases in the expected life-length have taken place in most other countries. There is a large literature dealing with the ageing of the population and the consequences this ought to have for the design of pension schemes. ${ }^{1}$

It is well known that the average length of life has increased considerably in the western world during the last 150 years and more recently also in the less developed countries. However, another important change in the mortality process is that the standard deviation of the length of life has decreased. Sweden has unusually good historical demographic statistics, so it is possible to follow this development over time. As the mortality among infants has a large influence both on the expected length of life and on the standard deviation, it is customary to calculate the standard deviation (or variance) in the length of life for those who have survived until at least age 10 . This measure is usually denoted $s_{10}$. For Sweden, $s_{10}$ was 21 around 1750 and had decreased to around 12.5 in year $2000 .^{2}$ There is also a large crosscountry variation in the standard deviation of life-length. This is particularly so if one compares developed and less developed countries, although there is variation also between developed countries. For instance, while Sweden has the most equal distribution of life-length with $S_{10}$ being around 12.5 years, the U.S. has one of the most unequal distributions among developed countries with a standard deviation, $s_{10}$, of 15 years. ${ }^{3}$

How would the optimal retirement age as well as the individual contribution to and benefit from the pension system respond to changes in the standard deviation of the length of life?

\footnotetext{
${ }^{1}$ This literature focuses on a variety of issues such as how the pension system affects retirement incentives at the individual level and labor supply behavior among the elderly (e.g., Gruber and Wise, 1999; Coile and Gruber, 2007), the optimal legal retirement age (Lacomba and Lagos, 2006) as well as the direction of reforms of social security (Diamond, 2005; Diamond and Orszag, 2005).

2 See Edwards and Tuljapurkar (2005, p. 654).

${ }^{3}$ See Edwards and Tuljapurkar (2005, p. 653).
} 
This, of course, depends on what we see as the reason for having a public pension scheme. Many alternative motives for public pension schemes have been discussed over time. One is that the market for annuities is not well functioning. It is, therefore, difficult for individuals to handle the uncertainty of the length of life. How much should be saved for the old age? How should individuals plan their consumption path in the old age? One role for a public pension scheme is to mitigate the problems associated with an uncertain length of life. It is this property that we focus on in the present paper. Our analysis shows that the standard deviation of the length of life has important implications for the optimal retirement age. The nature of this influence is, in turn, quite complex and depends crucially on individuals' risk aversion with respect to the number of years they plan to spend in retirement. An interesting policy implication of our analysis is that Sweden and the US should have different retirement ages due to differences in the standard deviation of life-length, even if we were to disregard all other differences between the two countries. As far as we know, the connection between the standard deviation of life-length and the optimal retirement age has not been examined before. ${ }^{4}$

To obtain a tractable model, we make several simplifying assumptions, the details of which will be laid out in section 2 below. One such simplification is that the individuals have no better knowledge about their own mortality than the policy maker (i.e. we abstract from asymmetric information); another is that the individuals' life-time utility functions exhibit temporal risk neutrality. ${ }^{5}$ In our model, the objective of the policy maker is to design the pension scheme in such a way that the expected lifetime utility faced by the representative consumer is maximized. Part of the solution to this problem is obtained by providing a certain consumption stream during the old age independently of how old an individual becomes. We shall both consider a first best framework where the government exercises full control over the resource allocation by deciding upon individual consumption, labor supply and retirement ages, as well as two different second best models where the government raises revenue by using a tax (or pension fee) proportional to labor income to finance a pension-benefit per year spent in retirement. One of the second best models contains a mandatory retirement age

\footnotetext{
${ }^{4}$ There are studies focusing on other aspects of the variation in the length of life between individuals. For example, Bommier et al. (2007) consider redistribution between individuals with different life-lengths. A crucial assumption in their work is that the individual life-time utilities exhibit temporal risk aversion.

${ }^{5}$ We also abstract from other sources of asymmetric information, such as unobserved differences in the ability to work during old age. Cremer et al. (2004) consider a model where the productivity and health status are private information and vary between consumers. They show that the second best optimal policy may imply a distortion of the retirement behavior.
} 
decided upon by the government, while the retirement age is a private decision-variable in the other. Real world pension systems often contain elements of both mandatory retirement (typically in the form of a lowest age when pension benefits become available) and individual retirement choices. To simplify the analysis, and capture how uncertainty with respect to the length of life affects the retirement age, we consider mandatory retirement and private retirement choices as two separate regimes.

The rest of this paper is organized as follows. In section 2, we present the model of individual behavior. Section 3 deals with the first best decision-problem and solution; in particular, we examine how the resource allocation responds to a change in the standard deviation of the length of life (as well as a change in the average length of life). In Sections 4 and 5, we consider a simple pension scheme in combination with a choice of retirement age, which is either made by the government (Section 4) or the individual consumer (Section 5). The pension system is such that the individual pays a tax (or pension fee) proportional to the labor income when young and receives a pension benefit when old. We use both versions of the model to analyze how the optimal pension fee, old-age benefit and retirement age depend on the standard deviation of the length of life. Section 6 concludes.

\section{The Model}

Consider a representative individual with preferences over the life-time consumption, the number of years spent in retirement, and the time spent on leisure while being part of the labor force, respectively. The assumption that the individual derives utility from the number of years spent in retirement is justified by the observation that the step from being a worker to being retired opens up a whole new spectrum of opportunities regarding time-use (e.g., developing new, and time-consuming, hobbies) as well as implies fewer restrictions on the residential choice. As a consequence, the utility associated with retirement may differ in a fundamental way from the utility of leisure during the working-life, which motivates that these two aspects of "non-working time" are treated separately. We assume that the utility function takes a quasi-linear form

$$
\sum_{t=1}^{T} C_{t}+P(T-R)+\sum_{t=1}^{R} U\left(H-h_{t}\right)
$$


where $C$ is annual consumption, $T$ the length of life, $R$ the retirement age and $h$ the annual hours of work. The term $H$ is interpretable as a fixed time endowment per period. The function $U\left(H-h_{t}\right)$ shows the utility of leisure in period $t$. The number of years spent in retirement is given by $T-R$ and the utility derived from the number of years spent in retirement is represented by the function $P(T-R)$. We assume that the functions $P(\cdot)$ and $U(\cdot)$ are increasing and strictly concave in their respective argument. The properties of the function $P(\cdot)$ drive many of our results; in particular, the sign of the third derivative will determine the sign of important comparative statics. We assume here that the length of life is a random variable in the sense that $T=\bar{T}+\gamma \varepsilon$, where $\bar{T}$ is the expected life-length, $\varepsilon$ a random variable with mean zero and unit variance, and $\gamma>0$ a parameter. This means that $\gamma$ is interpretable as the standard deviation of the length of life.

In the absence of any pension system, the life-time budget constraint facing the individual can be written as

$$
\sum_{t=1}^{R} w_{t} h_{t}-\sum_{t=1}^{T} C_{t}=0
$$

where $w$ is the hourly gross wage rate. In the next three sections, we use this basic model to analyze relationships between, on the one hand, the optimal retirement age and pension design and, on the other, the standard deviation of the length of life.

\section{A First Best Approach}

We start by considering a first best decision-problem, where the policy maker decides upon the consumption, hours of work and retirement age for a large number of identical individuals. To simplify the analysis, and be able to focus on the relationship between the retirement age and standard deviation of life-length, we assume that the consumption is equal during all years, and that the hours of work are constant during the years spent working.

Since the age of death is a stochastic variable, the budget constraint facing an individual will be stochastic as well. However, we assume that the number of individuals in the economy as a whole is large enough to imply that the resource constraint at the aggregate level can be 
treated as deterministic. The resource constraint for the policy maker can, therefore, be written as

$$
\bar{T} C-R w h=0 .
$$

The objective of the policy maker is to maximize the expected utility of a typical individual, i.e.

$$
E[T C+P(T-R)+R V(H-h)]=\bar{T} C+E[P(T-R)]+R U(H-h)
$$

where $E$ denotes the expectations operator. Using $T=\bar{T}+\gamma \varepsilon$, where $E(\varepsilon)=0$ and $\operatorname{Var}(\varepsilon)=1$, and then substituting equation (3) into equation (4), we can write the optimization problem of the policy maker as

$$
\underset{R, h}{\operatorname{Max}} R w h+E[P(T-R)]+R U(H-h)
$$

The first order conditions for $R$ and $h$ become

$$
\begin{aligned}
& w h-E\left[P^{\prime}(T-R)\right]+U(H-h)=0 \\
& w-U^{\prime}(H-h)=0 .
\end{aligned}
$$

We can then derive the following functions for the optimal retirement age and hours of work;

$$
\begin{aligned}
& R=R(\stackrel{+}{w}, \stackrel{+}{T}, \gamma) \\
& h=h(\stackrel{+}{w})
\end{aligned}
$$

in which the sign of the comparative statics derivative (when the sign is unambiguous) is given above each argument. The comparative statics derivatives are presented in the Appendix. Equations (6) and (7) show that an increase in the wage rate leads to an increase in the retirement age and an increase in the hours of work per period when participating in the labor market: in other words, both labor supply dimensions are modified in response to a 
change in the wage rate. A change in average length of life, on the other hand, only leads to an increase in the retirement age, while the hours of work per period remain unaffected. This is a consequence of quasi-linearity, which means that a higher $\bar{T}$ does not affect the tradeoff between consumption and leisure within a given period. In fact, as we show in the Appendix, our model implies $\partial R / \partial \bar{T}=1$, so an increase in the life expectancy by one year means that the retirement is postponed by one year as well. The reason as to why $\gamma$ does not affect the hours of work is analogous; it does not affect the tradeoff between consumption and leisure.

The qualitative effect on the retirement age of an increase in the standard deviation of lifelength, $\gamma$, is ambiguous in general. One can show that $\operatorname{sign} \partial R / \partial \gamma=-\operatorname{sign} \operatorname{cov}(\varepsilon, P ")$. If $\operatorname{cov}\left(\varepsilon, P^{\prime \prime}\right)>0(<0)$, then $\partial R / \partial \gamma<0 \quad(>0)$. A sufficient condition for $\operatorname{cov}\left(\varepsilon, P^{\prime \prime}\right)$ to be positive is that the sub-utility function capturing the preferences for the number of years spent in retirement, $P(\cdot)$, is characterized by constant or decreasing absolute risk aversion in the sense that

$$
-\frac{P^{\prime \prime}\left(A_{2}\right)}{P^{\prime}\left(A_{2}\right)} \leq-\frac{P^{\prime \prime}\left(A_{1}\right)}{P^{\prime}\left(A_{1}\right)} \text { for } A_{2}>A_{1} \text {. }
$$

With increasing absolute risk aversion, $\operatorname{cov}\left(\varepsilon, P^{\prime \prime}\right)$ can be either positive or negative.

In summary, we have derived the following results;

Proposition 1. In the first best, an increase (decrease) in the life-expectancy, $\bar{T}$, leads to an increase (decrease) in the optimal retirement age. If the preferences for the number of years spent in retirement are characterized by constant or decreasing absolute risk aversion, an increase (decrease) in the standard deviation of the length of life, $\gamma$, leads to a decrease (increase) in the optimal retirement age, i.e. $\partial R / \partial \gamma<0$.

The intuition behind the effect of a change in $\gamma$ is as follows: if the preferences for the number of years spent in retirement are characterized by constant or decreasing absolute risk aversion, there is no precautionary motive to delay the retirement age in response to increased uncertainty about the length of life. Instead, the optimal response will be to decrease the retirement age, which increases the likelihood that any consumer will be able to enjoy a period of retirement. Conversely, reduced uncertainty about the length of life, i.e. a decrease 
in $\gamma$, gives an incentive to postpone retirement, because the future benefits associated with retirement are less uncertain than before. With increasing absolute risk aversion, on the other hand, there is a precautionary motive for labor market participation (i.e. to earn more income) in response to increased uncertainty, which has a counteracting influence and renders the total effect ambiguous.

\section{A Second Best Model with Mandatory Retirement}

We begin this section by characterizing and solving the decision-problem faced by the individual, which is here limited to a choice of consumption and work hours (for a given retirement age). The final part concerns the policy-problem facing the government and its solution; in particular, how the (mandatory) retirement age, pension fee and old-age benefit respond to a change in the standard deviation of the length of life.

\section{Individual Behavior}

In reality, the consumption path of an individual may vary over the life-cycle; for instance, the planned consumption might be smaller for years where the probability of living is low than for years where the probability of living is high. Likewise the hours of work might vary between periods of the working life. To be able to focus attention on retirement behavior and pension-policy within a simple model, we abstract from these aspects by assuming (as we did in sections 2 and 3 above) that the consumption remains constant over the life-cycle, and that the hours of work per period are constant when the consumer participates in the labor market.

To be more specific, suppose that the individual lives for at most $T^{\max }$ years, and that the subutility function for consumption and leisure, respectively, has the property

$$
\sum_{t=1}^{T^{i}} \min C_{t}^{i} \text { and } \sum_{t=1}^{R^{i}} \min U\left(H-h_{t}^{i}\right) .
$$

This formulation will imply that the consumption is equalized over the life-cycle, and that the hours of work are constant over all years of work (as in the previous section). As a 
consequence, we eliminate the time-index, $t$, below. As before, the individual also receives utility from the number of years spent in retirement, $P\left(T^{i}-R^{i}\right)$.

The individual plans for the eventuality of living until the age of $T^{\max }$ years, although the probability of this event might be quite small. ${ }^{6}$ Therefore, the budget constraint takes the form

$$
R^{i} w h^{i}(1-\tau)+\left(T^{\max }-R^{i}\right) B-T^{\max } C^{i}=0
$$

In equation (8), $\tau$ is the contribution rate to the pension system, which is proportional to the labor income and paid during the time-period spent in the labor force, and $B$ a lump-sum pension per year spent in retirement. In this section, we consider a mandatory retirement age decided upon by the government, which is treated as exogenous by the individual. Therefore, the individual chooses consumption and work hours to maximize the expected utility subject to the budget constraint, i.e.

$$
\begin{aligned}
& \text { Max } E\left[T^{i} C^{i}+P\left(T^{i}-R^{i}\right)\right]+R^{i} U\left(H-h^{i}\right) \\
& C^{i}, h^{i}
\end{aligned}
$$

subject to equation (8). Since $T^{i}$ is stochastic, in all events except when $T^{i}=T^{\max }$ the individual will leave a "bequest". We assume this bequest gives no utility to the individual. It is a consequence of the uncertain life-time and the absence of a market for annuities. As before, we have $T^{i}=\bar{T}+\gamma \varepsilon^{i}$, where $E\left(\varepsilon^{i}\right)=0$ and $\operatorname{Var}\left(\varepsilon^{i}\right)=1$. By substituting the budget constraint into the objective function, the decision-problem facing individual $i$ can be written as

$$
\underset{h^{i}}{\operatorname{Max}} \frac{\bar{T}}{T^{\max }}\left[R^{i} w h^{i}(1-\tau)+\left(T^{\max }-R^{i}\right) B\right]+E\left[P\left(T^{i}-R^{i}\right)\right]+R^{i} U\left(H-h^{i}\right) .
$$

The first order condition for $h^{i}$ becomes

\footnotetext{
${ }^{6}$ This assumption is, of course, arbitrary. Our argument is that, if the individual does not consider the possibility that he/she may live to the age of $T^{\max }$, he/she may end up with too little resources during old age. As long as the individual plans for the possibility that his/her life may be longer than the average life-length, the final year assumed in the budget is not important.
} 


$$
\frac{\bar{T}}{T^{\max }} w(1-\tau)-U^{\prime}\left(H-h^{i}\right)=0
$$

As the individuals are identical ex-ante, they will choose the same number of work hours. Equation (10) is a slight modification of the standard labor supply condition saying that the marginal utility of consumption times the marginal wage rate per period spent working must be equal to the marginal utility of leisure. The weight $\bar{T} / T^{\max }$ attached to the marginal wage rate appears as a consequence of expected utility maximization in combination with the assumption that the consumer recognizes that he/she may reach the age $T^{\max }$. We can use equation (10) to derive the labor supplied when participating in the labor market as function of $\tau$ and $\bar{T}$ (suppressing the before-tax wage rate)

$$
h^{i}=h=h(\stackrel{-}{\bar{\tau}},)
$$

in which we have indicated the sign of each comparative static derivative above the corresponding argument. The intuition is straight forward: an increase in the contribution rate to the pension system reduces the marginal wage rate and, therefore, hours of work, while an increase in the life-expectancy provides an incentive to accumulate more income when participating in the labor market. Note also that $B$ and $\gamma$ do not affect the hours of work.

\section{The Government}

The government maximizes the expected utility for a typical cohort with ex-ante identical individuals by choosing the retirement age, $R$, contribution rate to the pension system, $\tau$, and pension benefit per year spent in retirement, $B$. We can write the objective function of the government in terms of the expected indirect utility function facing this typical individual

$$
\begin{aligned}
\breve{V}(\tau, B, R, \bar{T}, \gamma) & =\frac{\bar{T}}{T^{\max }}\left\{R w h(\tau, \bar{T})(1-\tau)+\left(T^{\max }-R\right) B\right\}+E[P(T-R)] \\
& +R U(H-h(\tau, \bar{T}))
\end{aligned} .
$$

The government's budget constraint is written as 


$$
\tau \operatorname{Rwh}(\tau, \bar{T})-[\bar{T}-R] B=0
$$

The budget constraint (13) builds on the assumption that all (unintended) bequests are returned lump-sum to the government.

By solving equation (13) for $B$ and substituting into equation (12), we can write the decisionproblem faced by the government as an unconstrained optimization problem in $\tau$ and $R$, i.e.

$$
\underset{\tau, R}{\operatorname{aax}} \frac{\bar{T}}{T^{\max }}\left\{R w h(1-\tau)+\left(T^{\max }-R\right) \frac{\tau R w h}{\bar{T}-R}\right\}+E[P(T-R)]+R U(H-h)
$$

where $T=\bar{T}+\gamma \varepsilon$, while the dependence of $h$ on $\tau$ and $\bar{T}$ has been suppressed for notational convenience. The first order conditions can then be written as

$$
\begin{array}{ll}
\tau: & -w h+\frac{T^{\max }-R}{\bar{T}-R}\left[w h+\tau w \frac{\partial h}{\partial \tau}\right]=0 \\
R: & \frac{\bar{T}}{T^{\max }}\left\{w h(1-\tau)+\frac{T^{\max }-\bar{T}}{(\bar{T}-R)^{2}} \tau R w h+\frac{T^{\max }-R}{\bar{T}-R} \tau w h\right\}-E\left[P^{\prime}(T-R)\right]+U(H-h)=0 .
\end{array}
$$

Equations (14a) and (14b) implicitly define the optimal contribution rate and retirement age, respectively. Therefore, by solving for the optimal contribution rate and retirement age, and then substituting into the public budget constraint in equation (13), we can derive the optimal pension benefit per year spent in retirement.

Our main concern here is how a change in the standard deviation of life-length affects the optimal retirement age, pension fee and old age benefit, respectively. With equations (13) and (14) at our disposal, we have derived the following result;

Proposition 2. If the preferences for the number of years spent in retirement are characterized by constant or decreasing absolute risk aversion, an increase (decrease), in the standard deviation of life-length leads to (i) a decrease (increase) in the retirement age, (ii) a decrease (increase) in the contribution rate to the pension system and (iii) a decrease 
(increase) in the pension benefit per year spent in retirement, i.e. $\partial R / \partial \gamma<0, \partial \tau / \partial \gamma<0$ and $\partial B / \partial \gamma<0$ at the second best optimum.

The calculations behind Proposition 2 are presented in the Appendix. The intuition is straight forward: with constant or decreasing absolute risk aversion, increased uncertainty about the length of life provides an incentive for the government to decrease the retirement age which, in turn, increases the likelihood that the consumer will be able to enjoy the benefits associated with retirement. Equivalently, reduced uncertainty about the length of life gives an incentive to postpone retirement. This is analogous to the corresponding result derived in a first best framework in Section 3.

Turning to the responses in the pension variables, note that a decrease in the retirement age (following an increase in the standard deviation of life-length) leads to a decrease in the planned consumption over the whole life-cycle, ceteris paribus, at the second best optimum with the contribution rate held constant. This can be seen by substituting $B=\tau R w h /(\bar{T}-R)$ from the public budget constraint into equation (8) and then differentiating with respect to $R$, in which case we obtain

$$
-\frac{\partial T^{\max } C}{\partial R}=-w h(1-\tau)-\frac{\partial\left[\left(T^{\max }-R\right)\{(\tau R w h) /(\bar{T}-R)\}\right]}{\partial R}<0 .
$$

A decrease in the contribution rate to the pension system counteracts this effect, as it leads to increased consumption, i.e.

$$
-\frac{\partial T^{\max } C}{\partial \tau}=-R w(1-\tau) \frac{\partial h}{\partial \tau}>0
$$

in which we have used that equations (14) are fulfilled at the second best optimum. As a consequence, there is an incentive for the policy maker to offset the lost consumption associated with early retirement by reducing the contribution rate or vice versa. This explains why the optimal retirement age and contribution rate to the pension system move in the same direction in response to increased or decreased uncertainty with respect to the length of life. Then, by using the public budget constraint, it follows that the pension benefit per year spent in retirement must move in the same direction as well.

Given the assumptions on which Proposition 2 is based, an interesting implication is that a country with a relatively low standard deviation of the length of life can be expected to have a 
higher retirement age and a more generous pension system (in terms of the levels of contribution rates and pension benefits) than a country with a relatively high standard deviation of the length of life, everything else held constant. For instance, our model predicts that Sweden ought to have a higher retirement age, higher contribution rates to the pension system and higher pension benefits per year spent in retirement than the U.S., because the standard deviation of life-length is higher in the U.S. than in Sweden.

Note also that if the preferences for the number of years spent in retirement are characterized by increasing absolute risk aversion (instead of constant or decreasing absolute risk aversion as in the preceding discussion), none of the three effects discussed in the proposition can be signed unambiguously. In other words, we can neither sign the effect on the optimal retirement age, nor the effects on the contribution rate and pension benefit, following a change in the standard deviation of the length of life. As before, this ambiguity is due to a precautionary motive to retire later (earlier) in response to increased (decreased) uncertainty.

The optimal policy-responses to an increase in the average length of life, $\bar{T}$, are ambiguous. In fact, and somewhat surprisingly, each of the two partial derivatives $\partial \tau / \partial \bar{T}$ and $\partial R / \partial \bar{T}$ can be either positive or negative in the second best model. There are two counteracting forces here (each of which is comprised of several mechanisms). First, the concavity of the function $P(\cdot)$ and the tax base effect of $\bar{T}$ (via increased work hours) constitute a joint incentive for the government to increase both $\tau$ and $R$ in response to a higher $\bar{T}$. The intuition is that (i) the expected marginal utility of an additional year spent on retirement decreases, and (ii) the government can collect more revenue without lowering the total lifetime consumption, $T^{\max } C$ (with $\bar{T}$ held constant, this variable decreases in response to a higher contribution rate). Second, a higher $\bar{T}$ lowers the pension benefit per year spent in retirement via the public budget constraint as well as reduces the budgetary gain of an increase in the pension fee. These effects work to decrease the optimal pension fee and retirement age. Note also that $\tau$ and $R$ need not necessarily move in the same direction, as the strengths of the mechanisms described above may vary between the policy-variables. The effect of an increase in $\bar{T}$ on the optimal pension benefit per year spent in retirement is, of course, also ambiguous.

\section{A Second Best Model with a Private Retirement Decision}


In this section, we relax the assumption that the retirement age is decided upon by the government and assume, instead, that the retirement age is a private decision variable. The government only decides upon the pension fee and pension benefit per year spent in retirement. Except for this difference, the structure of the model will be the same as above.

\section{Individual Behavior}

The individual chooses consumption, work hours and retirement age to maximize the expected utility subject to the budget constraint presented in equation (8). By substituting the budget constraint into the objective function, this decision-problem can be written as

$$
\underset{R^{i}, h^{i}}{\operatorname{Max}} \frac{\bar{T}}{T^{\max }}\left[R^{i} w h^{i}(1-\tau)+\left(T^{\max }-R^{i}\right) B\right]+E\left[P\left(T^{i}-R^{i}\right)\right]+R^{i} U\left(H-h^{i}\right)
$$

where (as before) $T^{i}=\bar{T}+\gamma \varepsilon^{i}$ with $E\left(\varepsilon^{i}\right)=0$ and $\operatorname{Var}\left(\varepsilon^{i}\right)=1$. The first order conditions for $h^{i}$ and $R^{i}$ become

$$
\begin{aligned}
& \frac{\bar{T}}{T^{\max }} w(1-\tau)-U^{\prime}\left(H-h^{i}\right)=0 \\
& \frac{\bar{T}}{T^{\max }}\left[w h^{i}(1-\tau)-B\right]-E\left[P^{\prime}\left(T^{i}-R^{i}\right)\right]+U\left(H-h^{i}\right)=0 .
\end{aligned}
$$

Equation (15a) takes the same form as its counterpart in Section 4, whereas equation (15b) is novel here and reflects the individual consumer's choice of retirement age. We can use equations (15a) and (15b) to derive the retirement age and the labor supplied when participating in the labor market as functions of $\tau, B, \bar{T}$ and $\gamma$. This gives

$$
\begin{aligned}
R^{i} & =R=R(\bar{\tau}, \bar{B}, \bar{T}, \gamma) \\
h^{i} & =h=h(\bar{\tau}, \overline{\bar{T}}) .
\end{aligned}
$$

The comparative statics are derived in the Appendix. We summarize the results as follows; 
Proposition 3. An increase in the contribution rate to the pension system, $\tau$, or pension benefit per year spent in retirement, $B$, will reduce the retirement age, and an increase in the contribution rate also leads to a decrease in the hours of work, ceteris paribus. With the contribution rate and pension benefit per year spent in retirement held constant, it follows that (i) an increase in the average length of life leads to increased hours of work as well as an increase (decrease) in the retirement age if $w h^{i}(1-\tau)-B>0(<0)$, and (ii) an increase in the standard deviation of the length of life leads to a decrease in the retirement age, if the preferences for the number of years spent in retirement, $P(\cdot)$, are characterized by constant or decreasing absolute risk aversion.

We now turn to the decision-problem faced by the government and, in particular, the optimal policy-responses to a change in the standard deviation of life-length.

\section{The Government}

As before, the government maximizes the expected utility for a typical cohort with ex-ante identical individuals. We write the objective function of the government as the expected indirect utility function of this typical individual

$$
\begin{aligned}
V(\tau, B, \bar{T}, \gamma) & =\frac{\bar{T}}{T^{\max }}\left\{R(\tau, B, \bar{T}, \gamma) w h(\tau, \bar{T})(1-\tau)+\left(T^{\max }-R(\tau, B, \bar{T}, \gamma)\right) B\right\} \\
& +E[P(T-R(\tau, B, \bar{T}, \gamma))]+R(\tau, B, \bar{T}, \gamma) U(H-h(\tau, \bar{T}))
\end{aligned}
$$

The budget constraint of the government is now given by

$$
G(\tau, B, \bar{T}, \gamma)=\tau R(\tau, B, \bar{T}, \gamma) w h(\tau, \bar{T})-[\bar{T}-R(\tau, B, \bar{T}, \gamma)] B=0,
$$

since the government must consider how the hours of work and retirement age (decisions made by the individual consumer) are affected by the policy-variables.

Therefore, the government behaves as if it chooses $\tau$ and $B$ to maximize the Lagrangean

$$
L=V(\tau, B, \bar{T}, \gamma)+\lambda G(\tau, B, \bar{T}, \gamma)
$$


where $\lambda$ is the Lagrange multiplier associated with the government's budget constraint. To avoid notational clutter, we write the first order conditions for $\tau$ and $B$ on the following compact form;

$$
\begin{aligned}
& V_{\tau}+\lambda G_{\tau}=0 \\
& V_{B}+\lambda G_{B}=0
\end{aligned}
$$

where the subscripts attached to the functions $V(\cdot)$ and $G(\cdot)$ denote partial derivatives. We assume that the second order condition

$$
\left|\begin{array}{ccc}
0 & G_{\tau} & G_{B} \\
G_{\tau} & V_{\tau \tau}+\lambda G_{\tau \tau} & V_{\tau B}+\lambda G_{\tau B} \\
G_{B} & V_{B \tau}+\lambda G_{B \tau} & V_{B B}+\lambda G_{B B}
\end{array}\right|>0
$$

is fulfilled, where a double subscript denotes second order partial derivative. The formulas for $V_{\tau}$ and $V_{B}$ are presented in the Appendix. Since $V_{\tau}<0$ and $V_{B}>0$, it follows that $G_{\tau}>0$ and $G_{B}<0$ at the second best optimum. In addition, if the preferences for the number of years spent in retirement are characterized by constant or decreasing absolute risk aversion in the sense described above, if it straight forward to show that $G_{\gamma}<0$.

In general, and contrary to the results derived in the previous section, the changes in the optimal contribution rate and pension benefit following a change in the standard deviation of the length of life are ambiguous here. This is not surprising, since the government has fewer instruments at its disposal here, i.e. the contribution rate and pension benefit must, in this case, also be used to influence the retirement age (as well as influence the hours of work and consumption, as in the previous section). To be able to derive an unambiguous result, we add the following assumption:

A1. (i) $G_{\tau \gamma} \geq 0$ and $G_{B \gamma} \geq 0$, and (ii) $V_{\tau B}+\lambda G_{\tau B}=V_{B \tau}+\lambda G_{B \tau} \leq 0$.

The first part of assumption A1 restricts the effects that a change in the standard deviation may have on the slopes of the public budget constraint in $\tau$ - and $B$-space. It means that an increase in $\gamma$ must not decrease the marginal budgetary gain of an increase in the contribution 
rate, and it must not increase the marginal budgetary loss of an increase in the pension benefit. This is also interpretable to mean that the budgetary incentive to tax and spend must not be deteriorated. The second part of assumption A1 places restraint on the cross derivatives: it ensures that the second order condition summarized by (21) is fulfilled. We can now derive the following result;

Proposition 4. If the preferences for the number of years spent in retirement are characterized by constant or decreasing absolute risk aversion, and under assumption A1, an increase in the standard deviation of life-length leads to an increase in the optimal contribution rate, i.e. $\partial \tau / \partial \gamma>0$ at the second best optimum.

The calculations underlying Proposition 4 are presented in the Appendix. As long as the preferences for the number of years spent in retirement are characterized by constant or decreasing absolute risk aversion, assumption A1 provides a sufficient, not necessary, condition for the optimal contribution rate to increase in response to an increase in the standard deviation of the length of life. The intuition behind Proposition 4 is as follows: with constant or decreasing absolute risk aversion, an increase in $\gamma$ unambiguously reduces the retirement age with $\tau$ and $B$ held constant and, therefore, the tax base. To compensate the lost revenue, the government increases the contribution rate to the pension system. However, it remains unclear whether the lower tax revenue due to a higher $\gamma$ exceeds, or falls short of, the revenue gain following the adjustment in the contribution rate. As a consequence, the pension benefit per year spent in retirement, $B$, may either increase or decrease. This also implies that the equilibrium effect of an increase or decrease in $\gamma$ on the retirement age remains ambiguous. ${ }^{7}$

The optimal policy-responses to an increase in the average length of life, $\bar{T}$, remain ambiguous here as well. As we saw above, an increase in the average life-length typically leads to an increase in the tax base both via increased retirement age and increased hours of work. This means that the tax revenue increases for a given contribution rate, and the government may respond either by an increase or decrease in the contribution rate and still

\footnotetext{
${ }^{7}$ Note that

$$
\frac{d R}{d \gamma}=\frac{\partial R}{\partial \gamma}+\frac{\partial R}{\partial \tau} \frac{\partial \tau}{\partial \gamma}+\frac{\partial R}{\partial B} \frac{\partial B}{\partial \gamma} .
$$

Although the first two terms on the right hand side are negative, the third is ambiguous. As a consequence, we were not able to sign the sum on the right hand side; let be that a positive value runs counter to intuition.
} 
obtain higher revenue than before. In addition, it is not clear whether the average number of years spent in retirement will increase or decrease. This also implies that the effect on the optimal pension benefit per year spent in retirement may change in either direction.

\section{Conclusion}

Contrary to earlier literature on the relationships between life-length, retirement age and public policy, which typically concentrates on effects of changes in the average length of life, the present paper focuses much attention on how the retirement age as well as the pension system (in terms of the contribution rate and pension benefit) ought to change in response to a change in the standard deviation of the length of life. Such a study has clear practical relevance both because this standard deviation has decreased substantially in most countries during the latest centuries, and because significant differences between countries still remain. As a consequence, it is important to understand how changes in the standard deviation of lifelength affects the optimal choice of retirement age as well as the optimal contribution to and benefit from the pension system. The present paper serves this purpose.

Our results show that the attitude towards risk constitutes a major determinant for how individual behavior and public policy may respond to a change in the standard deviation of life-length. Although this insight is not in itself very surprising, our relatively simple model allows us to derive several quite strong results. In a first best framework, where a benevolent government exercises perfect control over the individuals' consumption, labor supply and retirement decisions, the results show that a decrease in the standard deviation of life-length leads to an increase in the optimal retirement age, if the preferences for "the number of years spent in retirement” are characterized by constant or decreasing absolute risk aversion. The intuition is that reduced uncertainty about the length of life gives an incentive to postpone retirement, because the future benefits associated with retirement are less uncertain than before.

In a second best framework, where the government raises revenue via a contribution to the pension system (or pension fee) attached to the labor income to finance a uniform lump-sum benefit per year spent in retirement, we consider two possible scenarios; (i) the retirement age is mandatory and decided upon by the government, and (ii) the retirement age is a private decision-variable. In the first scenario, we are able to derive a strong result: if the preferences 
for the number of years spent in retirement are characterized by constant or decreasing absolute risk aversion, then the optimal retirement age, contribution rate and benefit per year spent in retirement all increase in response to a decrease in the standard deviation of lifelength. All else equal, this suggests that a country with a lower standard deviation of lifelength ought to have a higher retirement age and more generous pension system (in terms of contribution rates and old age benefits) than a country with a higher standard deviation of lifelength. In the second scenario, where the retirement age is a private decision-variable, the results are less clear cut. We are able to show that a decrease in the standard deviation of lifelength leads to an increase in the retirement age, with the contribution rate and pension benefit held constant, and - in a special case - that the optimal contribution rate decreases in response to a decrease in the standard deviation. Again, this presupposes constant or decreasing absolute risk aversion.

The ambiguity in the second scenario is not surprising, since the government has fewer policy instruments at its disposal in that case. As a consequence, it must use the contribution rate and pension benefit per year spent in retirement to exercise control over the individual choices of consumption, work hours and retirement age. In the first scenario, on the other hand, the retirement age is decided upon by the government, which means that the government may use the contribution rate and pension benefit solely to affect the labor supply and consumption behavior.

One interesting direction for future research would be to relax the (unrealistic) assumption that the government is as well informed about individual mortality as the individuals themselves. Instead, if we were to introduce asymmetric information, the second best resource allocation would be related to these asymmetries, and not to arbitrary restrictions on the set of policy instruments. As such, this would enable us to examine how the optimal use of a nonlinear tax and pension system responds to increased variation in the length of life, which is arguably a realistic extension. Another interesting issue refers to the optimal combination of fully-funded and pay-as-you-go pensions, when the length of life is uncertain. We leave these and other extensions for future research.

\section{Appendix}

\section{First Best Resource Allocation}


Let $\Omega=E\left[P^{\prime \prime}(T-R)\right] U$ " $(H-h)>0$. The comparative statics become

$$
\begin{aligned}
& \frac{\partial R}{\partial w}=\frac{-h U^{\prime \prime}(H-h)}{\Omega}>0 \\
& \frac{\partial R}{\partial \bar{T}}=\frac{E\left[P^{\prime \prime}(T-R)\right] U^{\prime \prime}\left(H-h^{i}\right)}{\Omega}=1 \\
& \frac{\partial R}{\partial \gamma}=\frac{E\left[\varepsilon P^{\prime \prime}(T-R)\right] U^{\prime \prime}(H-h)}{\Omega} \\
& \frac{\partial h}{\partial w}=\frac{-E\left[P^{\prime \prime}(T-R)\right]}{\Omega}>0 .
\end{aligned}
$$

Second Best Model with Mandatory Retirement

Let us use $\Lambda$ as a short notation for the objective function faced by the government is Section 4. Therefore,

$$
\Lambda=\frac{\bar{T}}{T^{\max }}\left\{R w h(1-\tau)+\left(T^{\max }-R\right) \frac{\tau R w h}{\bar{T}-R}\right\}+E[P(T-R)]+R U(H-h),
$$

where the dependence of $h$ on $\tau$ and $\bar{T}$ has been suppressed. The first order conditions $\Lambda_{\tau}=0$ and $\Lambda_{R}=0$ are given by equations (14a) and (14b), respectively. The second order conditions, i.e. $\Lambda_{\tau \tau}<0, \Lambda_{R R}<0$ and $\Phi=\Lambda_{\tau \tau} \Lambda_{R R}-\Lambda_{\tau R}^{2}>0$, are assumed to be fulfilled. Note that

$$
\Lambda_{\tau R}=\frac{\bar{T}}{T^{\max }} \frac{T^{\max }-\bar{T}}{(\bar{T}-R)^{2}}\left[R w h+\tau R w \frac{\partial h}{\partial \tau}\right]>0
$$

We can then use equations (14a) and (14b) to derive

$$
\begin{aligned}
& \frac{\partial \tau}{\partial \gamma}=-\frac{1}{\Phi} \Lambda_{\tau R} E\left[\varepsilon P^{\prime \prime}(T-R)\right] \\
& \frac{\partial R}{\partial \gamma}=\frac{1}{\Phi} \Lambda_{\tau \tau} E\left[\varepsilon P^{\prime \prime}(T-R)\right]
\end{aligned}
$$


If the preferences for the number of years spent in retirement are characterized by constant or decreasing absolute risk aversion, we have $E\left[\varepsilon P^{\prime \prime}(T-R)\right]>0$, so $\partial \tau / \partial \gamma<0$ and $\partial R / \partial \gamma<0$. Finally, the public budget constraint can be written as

$$
B=\frac{\tau R w h}{\bar{T}-R}
$$

If $E\left[\varepsilon P^{\prime \prime}(T-R)\right]>0$, we have

$$
\frac{\partial B}{\partial \gamma}=\frac{\bar{T} w h}{(\bar{T}-R)^{2}} \frac{\partial R}{\partial \gamma}+\frac{R w h}{\bar{T}-R} \frac{\partial \tau}{\partial \gamma}<0 .
$$

\section{Second Best Model with a Private Retirement Decision}

Let $\Omega^{i}=E\left[P^{\prime \prime}\left(T^{i}-R^{i}\right)\right] U^{\prime \prime}\left(H-h^{i}\right)>0$ and $\Gamma^{i}=\left(w h^{i}(1-\tau)-B\right) / T^{\max }-E\left[P^{\prime \prime}\left(T^{i}-R^{i}\right)\right]$. We can then derive the following responses at the individual level;

$$
\begin{aligned}
& \frac{\partial R^{i}}{\partial \tau}=\frac{\frac{\bar{T}}{T^{\max }} w h^{i} U^{\prime \prime}\left(H-h^{i}\right)}{\Omega^{i}}<0 \\
& \frac{\partial R^{i}}{\partial B}=\frac{\frac{\bar{T}}{T^{\max }} U^{\prime \prime}\left(H-h^{i}\right)}{\Omega^{i}}<0 \\
& \frac{\partial R^{i}}{\partial \bar{T}}=\frac{-\Gamma^{i} U^{\prime \prime}\left(H-h^{i}\right)}{\Omega^{i}} \\
& \frac{\partial R^{i}}{\partial \gamma}=\frac{E\left[\varepsilon^{i} P^{\prime \prime}\left(T^{i}-R^{i}\right)\right] U^{\prime \prime}\left(H-h^{i}\right)}{\Omega^{i}} \\
& \frac{\partial h^{i}}{\partial \tau}=\frac{E\left[P^{\prime \prime}\left(T^{i}-R^{i}\right)\right] w}{\Omega^{i}}<0 \\
& \frac{\partial h^{i}}{\partial \bar{T}}=\frac{-E\left[P^{\prime \prime}\left(T^{i}-R^{i}\right)\right] w(1-\tau) / T^{\max }}{\Omega^{i}}>0 .
\end{aligned}
$$


Turning to the government, we can use the first order conditions for the individuals to derive the following properties of the functions $V(\cdot)$ and $G(\cdot)$;

$$
\begin{aligned}
& V_{\tau}=-\frac{\bar{T}}{T^{\max }} R w h<0 \\
& V_{B}=\frac{\bar{T}}{T^{\max }}\left[T^{\max }-R\right]>0 \\
& V_{\tau B}=-\frac{\bar{T}}{T^{\max }} \frac{\partial R}{\partial B} w h \\
& V_{B \tau}=-\frac{\bar{T}}{T^{\max }} \frac{\partial R}{\partial \tau} \\
& V_{\tau \bar{T}}=-\frac{1}{T^{\max }} r w h-\frac{\bar{T}}{T^{\max }}\left[\frac{\partial R}{\partial \bar{T}} w h+R w \frac{\partial h}{\partial \bar{T}}\right] \\
& V_{\tau \gamma}=-\frac{\bar{T}}{T^{\max }} \frac{\partial R}{\partial \gamma} w h \\
& V_{B \bar{T}}=\frac{1}{T^{\max }}\left[T^{\max }-R\right]-\frac{\bar{T}}{T^{\max }} \frac{\partial R}{\partial \bar{T}} \\
& V_{B \gamma}=-\frac{\bar{T}}{T^{\max }} \frac{\partial R}{\partial \gamma} \\
& G_{\tau}=R w h+\tau \frac{\partial R}{\partial \tau} w h+\tau R w \frac{\partial h}{\partial \tau}+\frac{\partial R}{\partial \tau} B>0 \\
& G_{B}=\tau \frac{\partial R}{\partial B}[w h+B]-[\bar{T}-R]<0 \\
& G_{\tau B}=\frac{\partial R}{\partial B} w h+\tau \frac{\partial^{2} R}{\partial \tau \partial B}[w h+B] w h+\tau \frac{\partial R}{\partial B} w \frac{\partial h}{\partial \tau}+\frac{\partial R}{\partial \tau} \\
& G_{\bar{T}}=\frac{\partial R}{\partial \bar{T}}[\tau w h+B]+\tau R w \frac{\partial h}{\partial \bar{T}}-B \\
& G_{\gamma}=\frac{\partial R}{\partial \gamma}[\tau w h+B] \\
& G_{\tau \bar{T}}=\frac{\partial R}{\partial \bar{T}} w h+R w \frac{\partial h}{\partial \bar{T}}+\tau \frac{\partial^{2} R}{\partial \tau \partial \bar{T}} w h+\tau \frac{\partial R}{\partial \tau} w \frac{\partial h}{\partial \bar{T}}+\tau \frac{\partial R}{\partial \bar{T}} w \frac{\partial h}{\partial \tau} \\
& +\tau R w \frac{\partial^{2} h}{\partial \tau \partial \bar{T}}+\frac{\partial^{2} R}{\partial \tau \partial \bar{T}} \\
& G_{\tau \gamma}=\frac{\partial R}{\partial \gamma} w h+\tau \frac{\partial^{2} R}{\partial \tau \partial \gamma} w h+\tau \frac{\partial R}{\partial \gamma} w \frac{\partial h}{\partial \tau}+\frac{\partial^{2} R}{\partial \tau \partial \gamma} B
\end{aligned}
$$




$$
\begin{aligned}
G_{B \bar{T}} & =\tau \frac{\partial^{2} R}{\partial \tau \partial \bar{T}} w h+\tau \frac{\partial R}{\partial B} w \frac{\partial h}{\partial \bar{T}}+\frac{\partial^{2} R}{\partial B \partial \bar{T}} B-1+\frac{\partial R}{\partial \bar{T}} \\
G_{B \gamma} & =\tau \frac{\partial^{2} R}{\partial B \partial \gamma}[w h+B]+\frac{\partial R}{\partial \gamma} .
\end{aligned}
$$

Differentiating equation system (20a) and (20b) with respect to $\lambda \tau, B, \bar{T}$ and $\gamma$, while using

$$
\Delta=\left|\begin{array}{ccc}
0 & G_{\tau} & G_{B} \\
G_{\tau} & V_{\tau \tau}+\lambda G_{\tau \tau} & V_{\tau B}+\lambda G_{\tau B} \\
G_{B} & V_{B \tau}+\lambda G_{B \tau} & V_{B B}+\lambda G_{B B}
\end{array}\right|>0
$$

gives the comparative statics derivatives

$$
\begin{aligned}
& \frac{\partial \tau}{\partial \bar{T}}=\frac{G_{T}\left[G_{\tau} L_{B B}-G_{B} L_{\tau B}\right]+G_{B}\left[G_{B} L_{\tau \bar{T}}-G_{\tau} L_{B \bar{T}}\right]}{\Delta} \\
& \frac{\partial B}{\partial \bar{T}}=\frac{G_{\bar{T}}\left[G_{B} L_{\tau \tau}-G_{\tau} L_{\tau B}\right]+G_{\tau}\left[G_{\tau} L_{B \bar{T}}-G_{B} L_{\tau \bar{T}}\right]}{\Delta} \\
& \frac{\partial \tau}{\partial \gamma}=\frac{G_{\gamma}\left[G_{\tau} L_{B B}-G_{B} L_{\tau B}\right]+G_{B}\left[G_{B} L_{\tau \gamma}-G_{\tau} L_{B \gamma}\right]}{\Delta} \\
& \frac{\partial B}{\partial \gamma}=\frac{G_{\gamma}\left[G_{B} L_{\tau \tau}-G_{\tau} L_{\tau B}\right]+G_{\tau}\left[G_{\tau} L_{B \gamma}-G_{B} L_{\tau \gamma}\right]}{\Delta}
\end{aligned}
$$

where $L_{\tau \tau}=V_{\tau \tau}+\lambda G_{\tau \tau}$ and correspondingly for the other $L$-derivatives.

\section{References}

Bommier, A., Leroux, M-L. and Lozachmeur, J-M. (2007) Uncertain Lifetime, Redistribution and Nonlinear Pricing of Annuities. Mimeo.

Coile, C. and Gruber, J. (2007) Future Social Security Entitlements and the Retirement Decision. Review of Economics and Statistics 89, 234-246.

Cremer, H., Lozachmeur, J-M. and Pestieau, P. (2004) Social Security, Retirement Age and Optimal Income Taxation. Journal of Public Economics 88, 2259-2281.

Diamond, P. (2005) Pensions for an Ageing Population. NBER Working Papers: 118777.

Diamond, P. and Orszag, R. (2005) Saving Social Security. Journal of Economic Perspectives 19, 11-32. 
Edwards, R.D and Tuljapurkar, S. (2005) Inequality in Life Spans and a New Perspective on Mortality Convergence Across Industrialized Countries. Population and Development Review 31, 645-675.

Gruber, J. and Wise, D. (1999) Social Security and Retirement around the World. Chicago: The University of Chicago Press.

Lacomba, J. and Lagos, F. (2006) Population Ageing and Legal Retirement Age. Journal of Population Economics 19, 507-519. 


\section{CESifo Working Paper Series}

for full list see www.cesifo-group.org/wp

(address: Poschingerstr. 5, 81679 Munich, Germany, office@cesifo.de)

3140 Lawrence M. Kahn, Labor Market Policy: A Comparative View on the Costs and Benefits of Labor Market Flexibility, July 2010

3141 Ben J. Heijdra, Jochen O. Mierau and Laurie S.M. Reijnders, The Tragedy of Annuitization, July 2010

3142 Erkki Koskela, Outsourcing Cost and Tax Progression under Nash Wage Bargaining with Flexible Outsourcing, July 2010

3143 Daniel Osberghaus and Christiane Reif, Total Costs and Budgetary Effects of Adaptation to Climate Change: An Assessment for the European Union, August 2010

3144 Philip E. Graves, Benefit-Cost Analysis of Environmental Projects: A Plethora of Systematic Biases, August 2010

3145 Sabrina Di Addario and Daniela Vuri, Entrepreneurship and Market Size. The Case of Young College Graduates in Italy, August 2010

3146 Shoshana Amyra Grossbard and Alfredo Marvăo Pereira, Will Women Save more than Men? A Theoretical Model of Savings and Marriage, August 2010

3147 Jarko Fidrmuc, Time-Varying Exchange Rate Basket in China from 2005 to 2009, August 2010

3148 Ilja Neustadt and Peter Zweifel, Is the Welfare State Sustainable? Experimental Evidence on Citizens' Preferences for Redistribution, August 2010

3149 Marcus Dittrich and Andreas Knabe, Wage and Employment Effects of Non-Binding Minimum Wages, August 2010

3150 Shutao Cao, Enchuan Shao and Pedro Silos, Fixed-Term and Permanent Employment Contracts: Theory and Evidence, August 2010

3151 Ludger Woessmann, Cross-Country Evidence on Teacher Performance Pay, August 2010

3152 Lorenzo C. G. Pozzi, Casper G. de Vries and Jorn Zenhorst, World Equity Premium Based Risk Aversion Estimates, August 2010

3153 Volker Grossmann, Thomas M. Steger and Timo Trimborn, Dynamically Optimal R\&D Subsidization, August 2010

3154 Alexander Haupt, Tim Krieger and Thomas Lange, A Note on Brain Gain and Brain Drain: Permanent Migration and Education Policy, August 2010 
3155 António Afonso and Christophe Rault, Long-run Determinants of Sovereign Yields, August 2010

3156 Franziska Tausch, Jan Potters and Arno Riedl, Preferences for Redistribution and Pensions. What can we Learn from Experiments?, August 2010

3157 Martin Kolmar and Andreas Wagener, Inefficient Group Organization as Optimal Adaption to Dominant Environments, August 2010

3158 Kai Carstensen, Klaus Wohlrabe and Christina Ziegler, Predictive Ability of Business Cycle Indicators under Test: A Case Study for the Euro Area Industrial Production, August 2010

3159 Horst Rottmann and Timo Wollmershäuser, A Micro Data Approach to the Identification of Credit Crunches, August 2010

3160 Philip E. Graves, Appropriate Fiscal Policy over the Business Cycle: Proper Stimulus Policies Can Work, August 2010

3161 Michael Binder and Marcel Bluhm, On the Conditional Effects of IMF Program Participation on Output Growth, August 2010

3162 Michael Binder, Qianying Chen, and Xuan Zhang, On the Effects of Monetary Policy Shocks on Exchange Rates, August 2010

3163 Felix J. Bierbrauer, On the Optimality of Optimal Income Taxation, August 2010

3164 Nikolaus Wolf, Europe's Great Depression - Coordination Failure after the First World War, September 2010

3165 Dan Kovenock and Brian Roberson, Conflicts with Multiple Battlefields, September 2010

3166 Jean-Pierre Ponssard and Catherine Thomas, Capacity Investment under Demand Uncertainty. An Empirical Study of the US Cement Industry, 1994-2006, September 2010

3167 Jørgen Juel Andersen, Jon H. Fiva and Gisle James Natvik, Voting when the Stakes are High, September 2010

3168 Michael Hoel, Is there a Green Paradox?, September 2010

3169 Scott Alan Carson, Nineteenth Century US African-American and White Female Statures: Insight from US Prison Records, September 2010

3170 Gil S. Epstein, Yosef Mealem and Shmuel Nitzan, Political Culture and Discrimination in Contests, September 2010

3171 Sara Fisher Ellison, Jeffrey Greenbaum and Wallace P. Mullin, Diversity, Social Goods Provision, and Performance in the Firm, September 2010 
3172 Silvia Dominguez-Martinez, Randolph Sloof and Ferdinand von Siemens, Monitoring your Friends, not your Foes: Strategic Ignorance and the Delegation of Real Authority, September 2010

3173 Marcus Dittrich and Beate Schirwitz, Union Membership and Employment Dynamics: A Note, September 2010

3174 Francesco Daveri, Paolo Manasse and Danila Serra, The Twin Effects of Globalization - Evidence from a Sample of Indian Manufacturing Firms, September 2010

3175 Florian Blöchl, Fabian J. Theis, Fernando Vega-Redondo and Eric O’N. Fisher, Which Sectors of a Modern Economy are most Central?, September 2010

3176 Dag Morten Dalen, Marilena Locatelli and Steinar Strøm, Longitudinal Analysis of Generic Substitution, September 2010

3177 Armin Falk, Stephan Meier and Christian Zehnder, Did we Overestimate the Role of Social Preferences? The Case of Self-Selected Student Samples, September 2010

3178 Christian Fahrholz and Cezary Wójcik, The Bail-Out! Positive Political Economics of Greek-type Crises in the EMU, September 2010

3179 Klaus Abberger and Wolfgang Nierhaus, The Ifo Business Cycle Clock: Circular Correlation with the Real GDP, September 2010

3180 Walter Krämer and Gerhard Arminger, "True Believers" or Numerical Terrorism at the Nuclear Power Plant, September 2010

3181 Bernard M.S. Van Praag, Dmitri Romanov and Ada Ferrer-i-Carbonell, Happiness and Financial Satisfaction in Israel. Effects of Religiosity, Ethnicity, and War, September 2010

3182 Dimitrios Koumparoulis and Paul De Grauwe, Public Capital, Employment and Productivity: An Empirical Investigation for Greece, September 2010

3183 John Whalley and Tanmaya Shekhar, The Rapidly Deepening India-China Economic Relationship, September 2010

3184 Andreas Schäfer and Thomas Steger, History, Expectations, and Public Policy: Economic Development in Eastern Germany, September 2010

3185 Thomas Eichner and Marco Runkel, Subsidizing Renewable Energy under Capital Mobility, September 2010

3186 Konstantinos Angelopoulos and James Malley, Fear of Model Misspecification and the Robustness Premium, September 2010

3187 Philip E. Graves, A Note on the Design of Experiments Involving Public Goods, September 2010 
3188 Glenn Ellison, How does the Market Use Citation Data? The Hirsch Index in Economics, September 2010

3189 Barbara Hanel and Regina T. Riphahn, The Employment of Mothers - Recent Developments and their Determinants in East and West Germany, September 2010

3190 Alexander Haupt and Silke Uebelmesser, Integration, Mobility, and Human Capital Formation, September 2010

3191 Vincenzo Galasso and Paola Profeta, When the State Mirrors the Family: The Design of Pension Systems, September 2010

3192 Stéphane Zuber and Geir B. Asheim, Justifying Social Discounting: The RankDiscounted Utilitarian Approach, September 2010

3193 Alexander Kemnitz, Educational Federalism and the Quality Effects of Tuition Fees, September 2010

3194 Claudia M. Buch, Sandra Eickmeier and Esteban Prieto, Macroeconomic Factors and Micro-Level Bank Risk, September 2010

3195 May Elsayyad and Kai A. Konrad, Fighting Multiple Tax Havens, September 2010

3196 Laszlo Goerke and Markus Pannenberg, Trade Union Membership and Dismissals, September 2010

3197 Ferdinand Mittermaier and Johannes Rincke, Do Countries Compensate Firms for International Wage Differentials?, September 2010

3198 John Boyd, Gianni De Nicoló and Abu M. Jalal, Bank Competition, Asset Allocations and Risk of Failure: An Empirical Investigation, September 2010

3199 Guido Heineck and Bernd Süssmuth, A Different Look at Lenin's Legacy: Trust, Risk, Fairness and Cooperativeness in the two Germanies, September 2010

3200 Ingvild Almås, Tarjei Havnes and Magne Mogstad, Baby Booming Inequality? Demographic Change and Earnings Inequality in Norway, 1967-2000, October 2010

3201 Thomas Aronsson and Sören Blomquist, The Standard Deviation of Life-Length, Retirement Incentives, and Optimal Pension Design, October 2010 